\title{
REVITALISASI KAWASAN ASRAMA HAJI DENGAN PENDEKATAN ARSITEKTUR ISLAM DI MAKASSAR
}

\author{
Irma Rahayu ${ }^{* 1}$, Wasilah $^{2}$, Idris Syukur ${ }^{3}$ \\ Jurusan Teknik Arsitektur Fakultas Sains \& Teknologi UIN-Alauddin Makassar \\ *1irma.rahayu@uin-alauddin.ac.id, ${ }^{2}$ wasilah@uin-alauddin.ac.id, 3; Idrissyukur@gmail.com
}

\begin{abstract}
Abstrak_ Kawasan Asrama Haji Makassar merupakan kompleks kegiatan keagamaan di mana di tempat ini adalah tempat embarkasi dan debarkasi bagi para calon haji sebelum di berangkatkan ke tanah suci, selain itu kawasan asrama haji ini terbuka untuk masyarakat umum baik untuk kegiatan pelatihan maupun kegiatan wisata religi. Dimana didalamnya terdapat kegiatan pendidikan berbasis agama islam. Sedangkan konsep perancangan bentuk bangunan pada kawasan asrama haji Makassar. akan dibuat nantinya berdasarkan dari transformasi sebuah bentuk dasar persegi yang akan diolah sesederhana mungkin. Hal ini dimaksud untuk menguatkan aspek kesederhanaan yang ada pada tema.
\end{abstract}

Kata kunci : Kawasan Asrama Haji; Makassar.

Abstract_Asrama Haji Makassar is a complex of religious activities where in this place is a place of embarkation and debarkation for the prospective hajj before departing to the holy land, on other hand, this area is opened to the general public both for training activities and religious tourism activities. Where in it there are activities based on Islamic religious education. While the concept of designing the form of buildings on the Asrama Haji of Makassar, Itself will be made later based on the transformation of a square base shape that be processed as simply as possible. This is intended to strengthen the simplicity aspects of the theme.

Keywords: Asrama Haji Area ; Makassar

\footnotetext{
${ }^{1}$ Jurusan Teknik Arsitektur Fakultas Sains \& Teknologi UIN-Alauddin Makassar

${ }^{2}$ Jurusan Teknik Arsitektur Fakultas Sains \& Teknologi UIN-Alauddin Makassar

${ }^{3}$ Jurusan Teknik Arsitektur Fakultas Sains \& Teknologi UIN-Alauddin Makassar
} 


\section{PENDAHULUAN}

Makassar merupakan ibu kota dari Provinsi Sulawesi Selatan. Statusnya sebagai ibu kota membuat Makassar menjadi pusat dari berbagai aspek, mulai dari perdagangan dan bisnis, kesehatan, olahraga dan juga merupakan pusat penyelenggaraan pemberangkatan calon jamaah Haji di wilayah Sulawesi Selatan dan sekitarnya. Adapun jumlah penduduk muslim di Sulawesi Selatan pada tahun 2015 adalah sebesar 7.200.938 dengan persentase 89,63\%. (Dokumen pemuda, di akses tanggal 28 Februari, pukuL 14.03 WITA). Melihat jumlah penduduk Sulawesi Selatan yang mayoritas memeluk agama Islam, maka tiap tahunnya pemerintah kota Makassar bekerjasama dengan Kementerian Agama memberangkatkan calon jamaah Haji.

Ibadah Haji sendiri dari segi bahasa berarti pergi ke Mekkah, bermaksud, menyengaja. Sedangkan menurut istilah, ibadah Haji berarti menyengaja atau pergi ke Ka'bah untuk melaksanakan amalan-amalan tertentu. Bagi umat Islam, ibadah Haji adalah rukun Islam kelima yang menjadi ibadah penyempurna setelah empat rukun lainnya setelah syahadat, sholat, zakat dan puasa. Menunaikan ibadah Haji di dua tanah suci Islam yaitu Makkah dan Madinah yang berada di wilayah Negara Arab Saudi. Hukumnya wajib satu kali seumur hidup bagi seorang muslim yang merdeka, baligh, berakal, dan mampu. Untuk menampung calon jamaah Haji yang akan diberangkatkan ke tanah suci, pemerintah Kota Makassar bekerjasama dengan Kementerian Agama R.I Dirjen penyelenggaraan Haji dan umroh membentuk Organisasai yang diberi nama Badan Pengelola Asrama Haji (BPAH) Embarkasi Makassar.

Asrama Haji Embarkasi Makassar ini sendiri berada pada kawasan bandara terpadu hal tersebut tertera pada RTRW Kota Makassar tahun 2010-2030, sehingga dalam proses pemberangkatan para jemaah Haji dapat lebih mudah karena akses menuju ke Bandara Internasional Hasanuddin jarak tempuhnya sangat dekat dari Asrama Haji. Namun, kondisi Asrama Haji Embarkasi Makassar saat ini sebagai pusat kegiatan aktifitas embarkasi/ debarkasi yaitu Asrama yang berfungsi untuk melayani calon jemaah Haji dari proses awal keberangkatan sampai kepulangan mengalami kendala hal ini disebabkan karena adanya beberapa pokok permasalahan. Seiring berjalannya waktu, Kawasan Asrama Haji terjadi kerusakan pada beberapa gedung Asrama hal ini dikarenakan oleh faktor usia bangunan dan faktor alam. Selain terjadinya kerusakan bangunan permasalahan lain yang terjadi adalah tidak tersedianya Tempat Pembuangan Sampah sementara (TPS). Hal ini mengakibatkan penumpukan sampah di samping gedung Asrama yang dapat menyebabkan gangguan kesehatan pada para calon jamaah Haji. Imbas lain yang ditimbulkan adalah kawasan ini nampak kumuh.

Dari data dan paparan di atas, maka ditarik kesimpulan bahwa untuk meningkatkan pelayanan ibadah Haji dan kenyamanan calon jamaah Haji Embarkasi Makassar maka dibutuhkan upaya penataan kembali kawasan asrama haji Makassar dan meredesain gedung Asrama Haji dan melengkapi fasilitas-fasilitas penunjang yang diharapkan dapat memadai dari segi pelayanan.

\section{METODOLOGI}

Metode yang digunakan dalam perancangan ini yaitu ;

1. Studi Literature.

Pada tahap ini penulis mengambil studi literatur dari buku-buku perpustakaan dan bukubuku lain yang berkaitan dengan judul untuk mendapatkan teori, spesifikasi, dan karakteristik serta aspek-aspek arsitektural yang dapat dijadikan landasan dalam proses perancangan. 
2. Studi Komparasi.

Pada tahap ini penulis mengambil studi banding melalui internet terhadap penataan kawasan asrama haji yang ada di Indonesia maupun luar negeri. Studi Lapangan. Pada tahap ini penulis melakukan survey langsung ke kawasan asrama haji Makassar dan mengamati lingkungan sekitar tapak guna menunjang dalam perencanaan.

3. Analisis.

Tahap ini, penulis melakukan beberapa analisis untuk mendapatkan hasil desain yang maksimal dalam perencanaan.

\section{A. Lokasi Perancangan}

\section{HASIL DAN PEMBAHASAN}

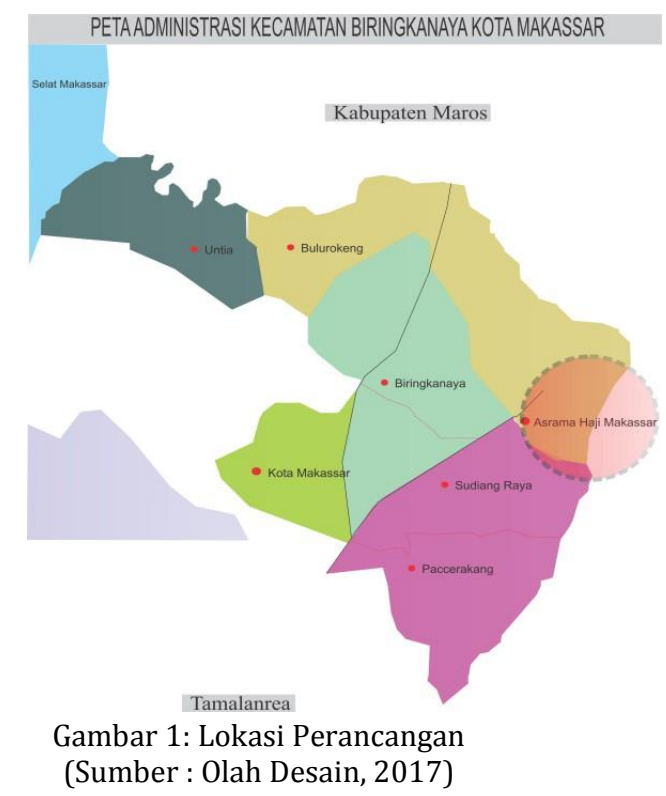

Lokasi perencanaan penataan Asrama Haji Embarkasi Makassar terletak di Kelurahan Sudiang, Kecamatan Biringkanaya, Kota Makassar. Asrama Haji Embarkasi Makassar ini sendiri berada pada kawasan bandara terpadu hal tersebut tertera pada RTRW Kota Makassar tahun 2010-2030, sehingga dalam proses pemberangkatan para jemaah haji dapat lebih mudah karena akses menuju ke Bandara Internasional Hasanuddin jarak tempuhnya sangat dekat dari asrama haji, hal ini sesuai sebagai pusat kegiatan aktifitas Embarkasi/ Debarkasi yaitu asrama yang berfungsi untuk melayani calon jemaah haji dari proses awal keberangkatan sampai kepulangan.

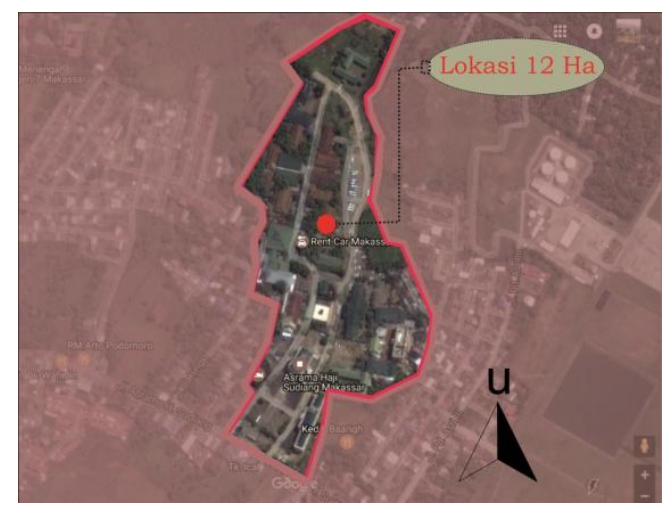

Gambar 2. Tapak Perancangan (Sumber : Olah Desain, 2017) 


\section{B. Tata Guna Lahan}

Tata guna lahan atau Land Use berpengaruh terhadap hubungan antara sirkulasi dan kepadatan aktivitas atau fungsi lahan dalam suatu kawasan. Tata guna lahan perlu dipertimbangkan 2 hal yakni pertimbangan dari segi umum dalam hal ini yaitu fasilitas penunjang dan aktivitas pejalan kaki yang akan menciptakan lingkungan yang lebih manusiawi. Penggunaan lahan di lokasi eksisting dapat dilihat pada gambar di bawah ini. Pada zona penerima ditempatkan main entrance, parkiran (bus, mobil pengunjung dan motor), serta pada zona penunjang ini dekat dengan gedung pengelola BPH yang terdiri dari bangunan aula, musholah, lapangan tenis, ruang ME (Mekanikal Elektrikal) dan pos jaga. Zona manasik haji dan Gedung BPH berada pada pusat tapak hal ini berdasarkan pertimbangan view, sedangkan area gedung wisma calon Jemaah haji, dapur, ruang makan, masjid dan fasilitas penunjang lainnya berada pada satu kawasan untuk memudahkan calon Jemaah haji.

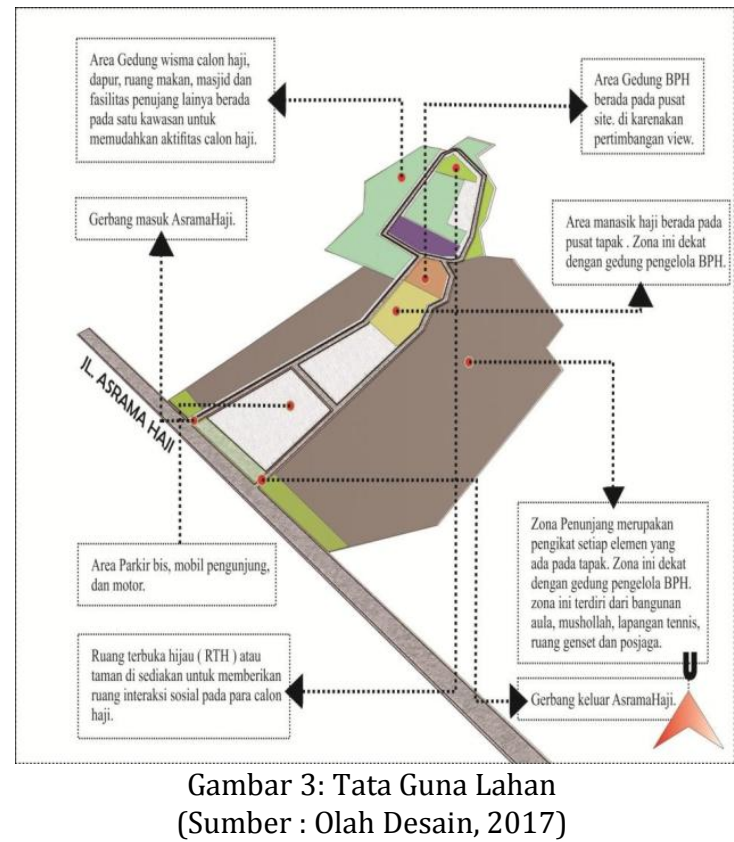

Tata massa bangunan merupakan produk dari penyelenggaraan bangunan gedung beserta lingkungannya sebagai wujud pemanfaatan ruang, meliputi berbagai aspek termasuk pembentukan citra/karakter fisik lingkungan, besaran, dan konfigurasi dari elemen-elemen: blok, kaveling/petak lahan, bangunan, serta ketinggian dan elevasi lantai bangunan, yang dapat menciptakan dan mendefinisikan berbagai kualitas ruang kota yang akomodatif terhadap keragaman kegiatan yang ada, terutama yang berlangsung dalam ruang-ruang publik. Bentuk dan massa bangunan ditentukan oleh ketinggian atau besarnya bangunan, penampilan bentuk maupun konfigurasi dari massa bangunannya. Kondisi bangunan di sekitar tapak sangat beragam, hal ini disebabkan karena perbedaan fungsi bangunan, penggunaan material dan pemilihan warna.

Asrama Haji Embarkasi Makassar ini sendiri menggunakan pola Radial, pola ini merupakan kombinasi antara pola linier dan terpusat. Pola radial sesuai dengan tapak Asrama Haji Embarkasi ini. 


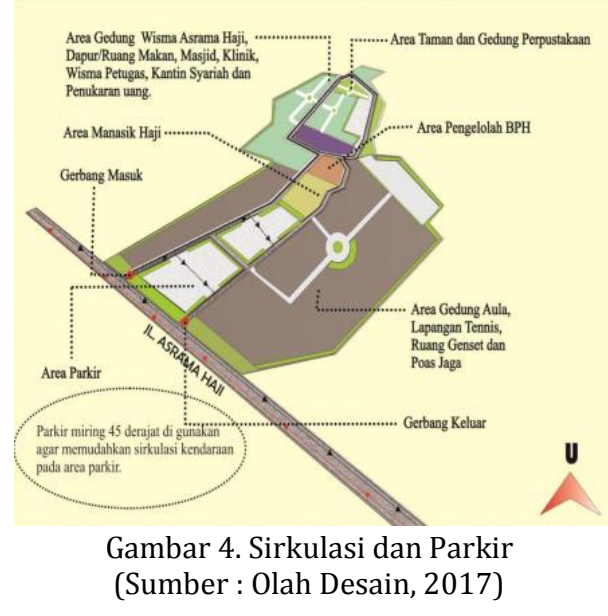

1. Sirkulasi kendaraan disekitar tapak di rekayasa agar tidak terjadi masalah dibeberapa titik seperti perempatan atau pertigaan disekitar tapak.

2. Pengguna Jl. Asrma Haji tidak terkendala macet karena lokasi jauh dari jalan poros sehingga memudahkan sirkulasi kendaraan disekitar tapak

3. Adapun material yang digunakan pada system parkir pada Kawasan Asrama Haji Makassar ini yakni menggunakan material Paving Blok serta penambahan vegetasi disekitar parkiran agar memberi kenyamanan bagi pengguna parkir itu sendiri.

\section{Jalur Pedestrian}

Pedestrian merupakan salah satu elemen penghubung yang merupakan ruang umum kota yang memungkinkan calon jemaah haji dapat saling berinteraksi satu sama lain. Jalur Pedestrian ini bertujuan untuk menghubungkan zona-zona yang ada di dalam area Asrama Haji Embarkasi. Adapun material dari jalur pedestrian itu sendiri yakni gabungan antara Paving Blok dan Beton. Desain jalur pedestrian utama di bagian dalam area Asrama Haji Embarkasi Makassar diberi penutup/ kanopi guna mencegah terkena paparan sinar matahari secara langsung serta didesain pada bagian langit-langit atapnya berlafaskan takbir yang mencerminkan nuansa Islami.

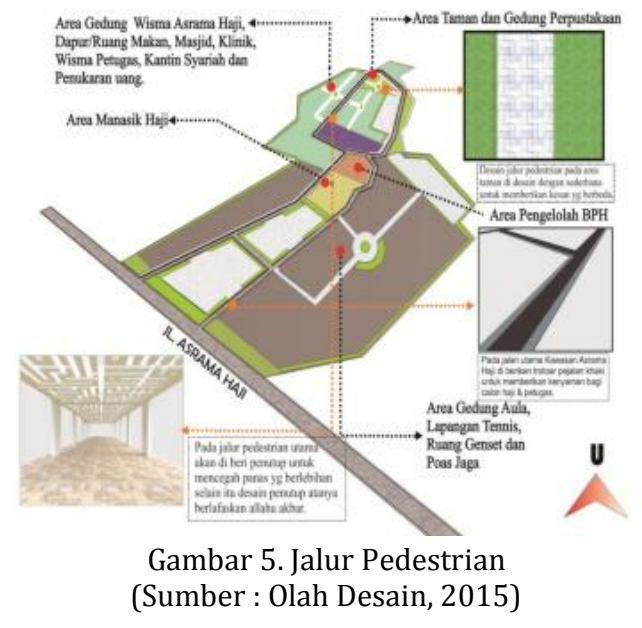

\section{Ruang Terbuka}

Desain Taman ini tetap mempertahankan vegetasi yang sudah ada, tetapi beberapa vegetasi yang terdapat dibeberapa bagian tapak telah termakan usia 
sehingga dapat membahayakan pengguna taman, adapun solusi yang digunakan yakni dengan meremajakan vegetasi yang ada tanpa mengurangi fungsi dari vegetasi tersebut. Adapun pohon besar yang digunakan seperti pohon mahoni, kiara payung, trembesi dan pohon tanjung, seperti pada gambar dibawah ini.

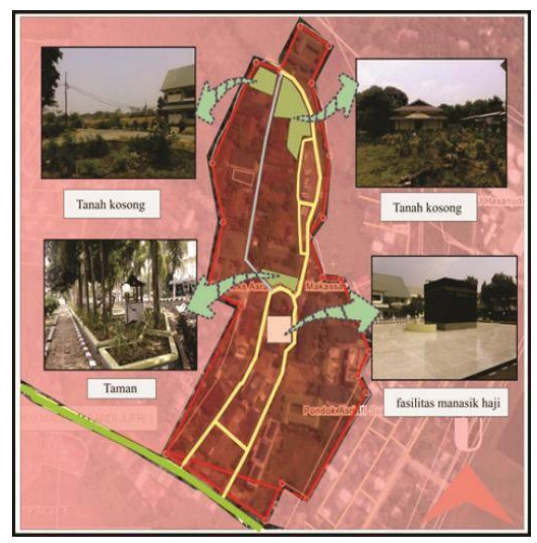

Gambar 6. Ruang Terbuka (Sumber : Olah Desain, 2017)

\section{E. Penanda}

Penanda atau signage pada Kawasan Asrama Haji Makassar ini terinspirasi dari bentuk perahu pinisi. Penanda terletak di beberapa bagian utma kawasan terutama di posisi strategis seperti dekat dengan bangunan utama dan bangunan penunjang seperti pada area parkir dan sebagainya. Seperti yang terlihat pada gambar di bawah ini :

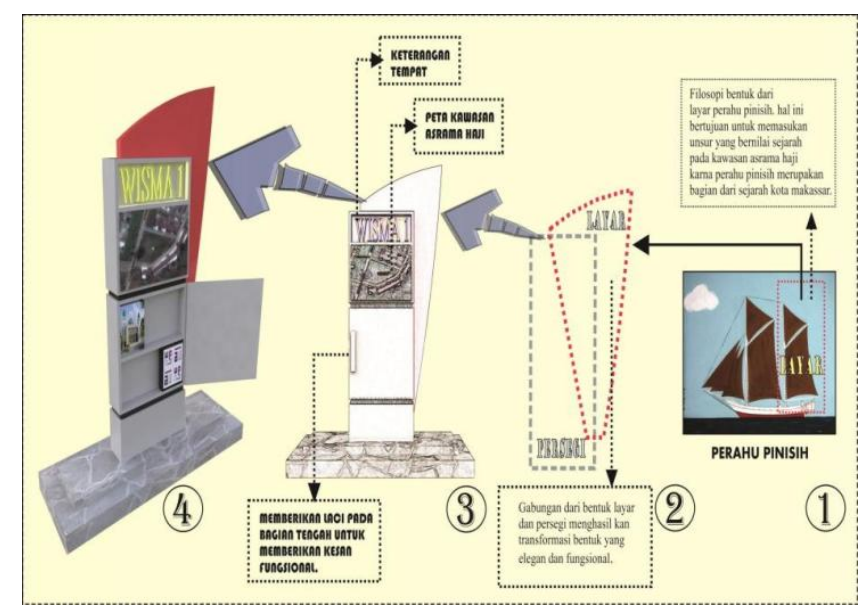

Gambar 7. Penanda

(Sumber : Olah Desain, 2017) 


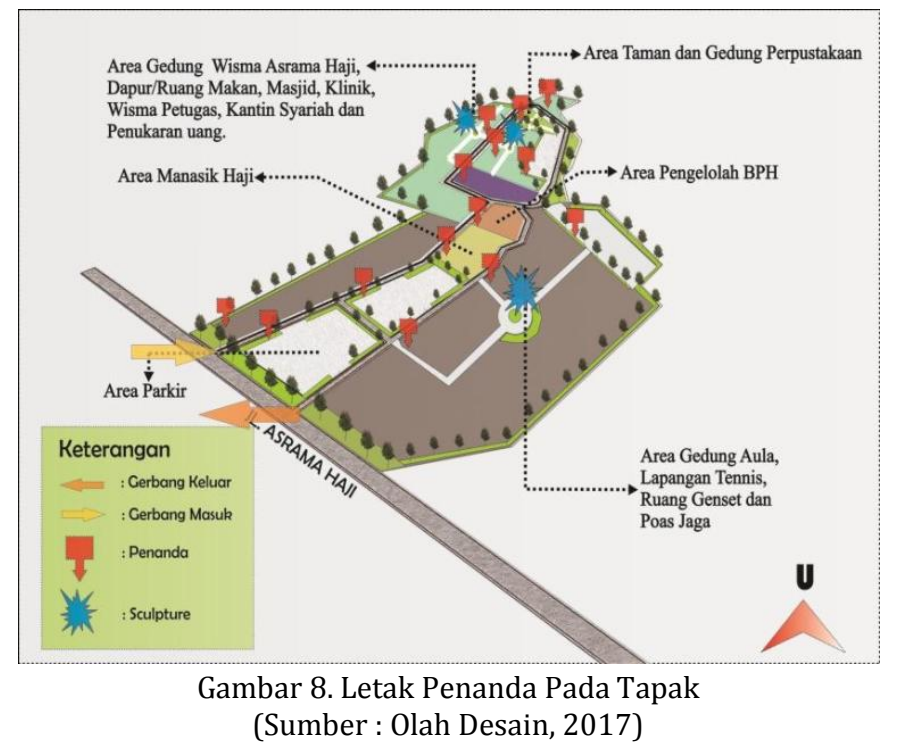

\section{F. Sculpture}

Sculpture terinspirasi dari kapal pinisi yang merupakan bagain penting dari sejarah Kota Makassar yakni menjadi kendaraan laut para raja-raja pada masa kerajaan untuk mengarungi lautan.

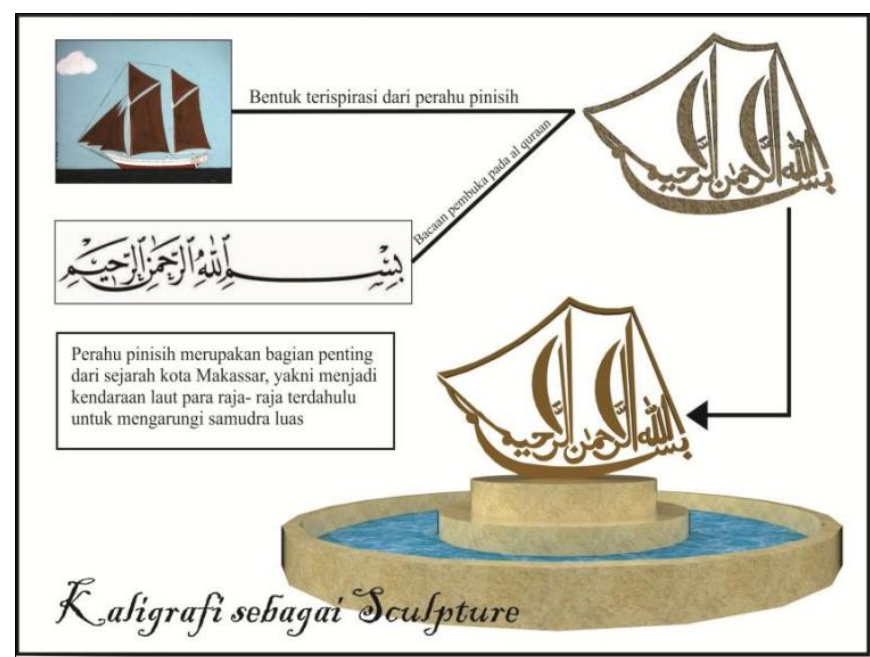

Gambar 9. Desain Sculpture

(Sumber : Olah Desain, 2017)

Selain Sculpture perahu pinisih di atas di area Asrama Haji Embarkasi Makassar ini terdapat menara penanda yang terinspirasi dari telunjuk pada tahyatull akhir yang memiliki makna ahwa Tuhan hanya ada 1 yaitu Allah SWT semata. Transformasi bentuk telunjuk didesain semirip mungkin dan pada setiap sisinya diberi tulisan kaligrafi berlafaskan takbir. 
Irma Rahayu*, Wasilah, Idris Syukur

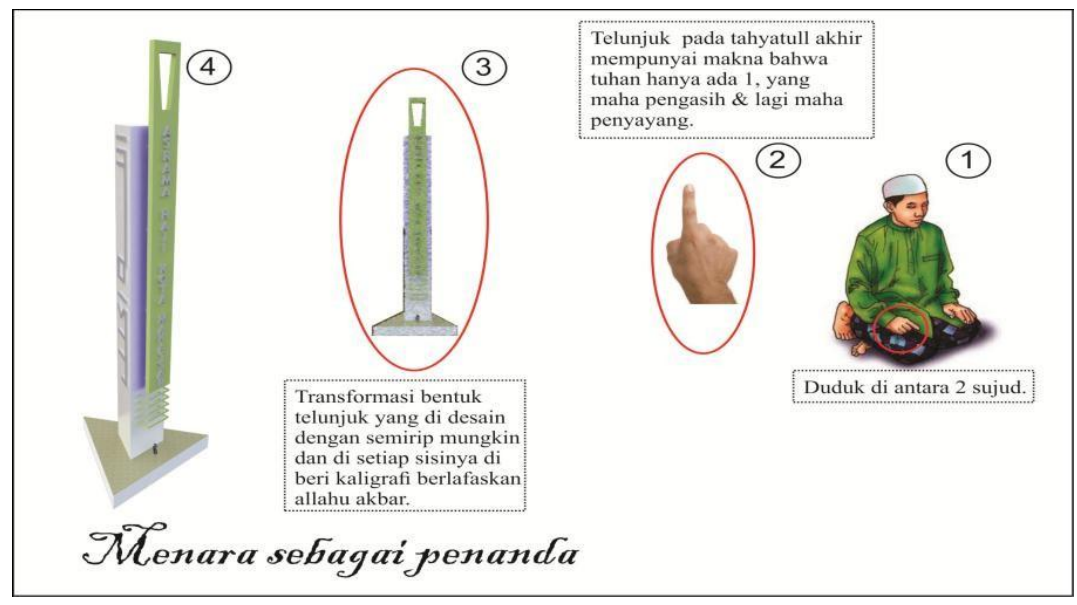

Gambar 10. Desain Sculpture Menara Sebagai Penanda

(Sumber : Olah Desain, 2017)

\section{G. Konsep Pendekatan Bentuk}

Berdasarkan beberapa pertimbangan akan kondisi yang ada saat ini dilokasi tapak maka diperoleh sebuah gagasan konsep pendekatan bentuk bangunan asrama calon Jemaah haji dengan mengadopsi bangunan yang sudah ada guna diterapkan pada bangunan asrama yang akan direnovasi atau dibangun dari awal agar tidak mengubah sinkronisasi antara bangunan yang satu dengan bangunan yang lainnya. Berikut pendekatan konsep bentuk bangunan asrama dapat dilihat pada gambar di bawah:

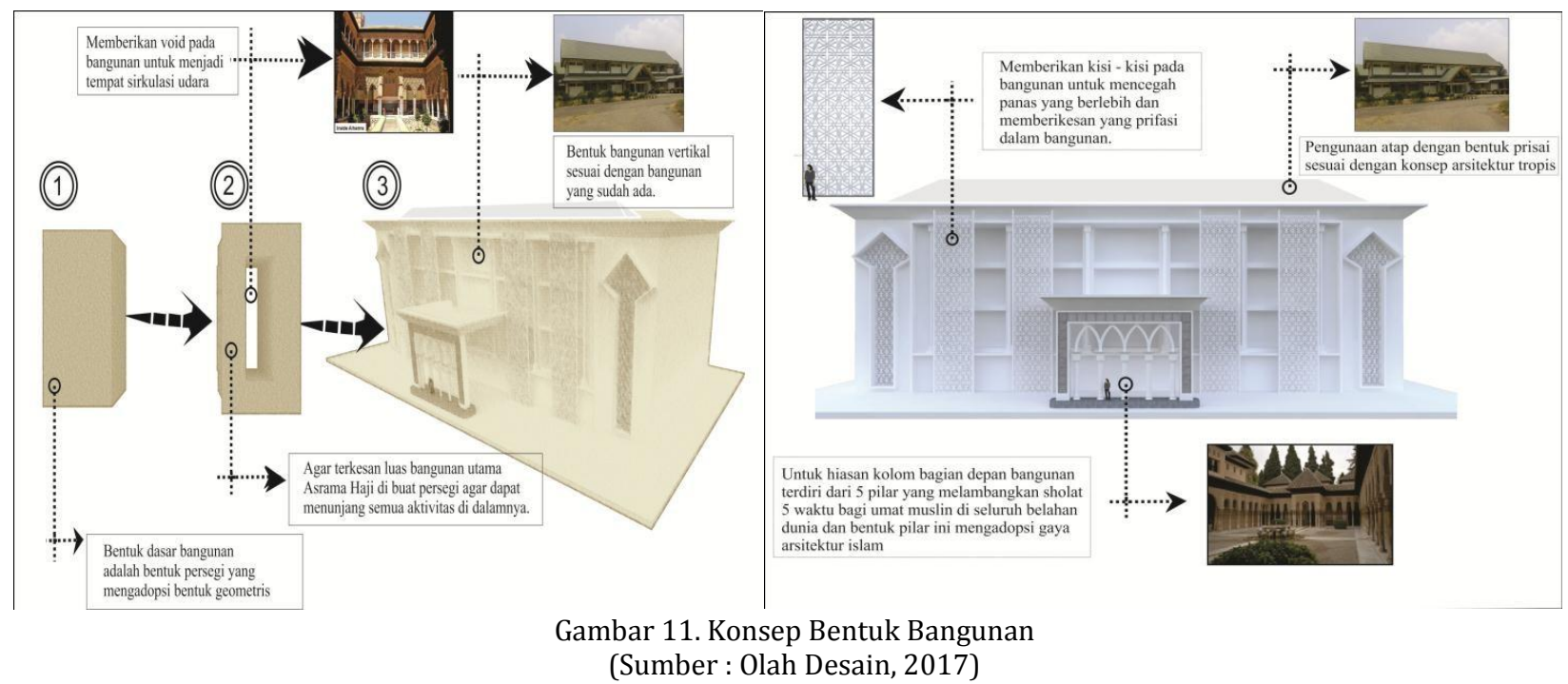




\section{H. Site Plan Kawasan}

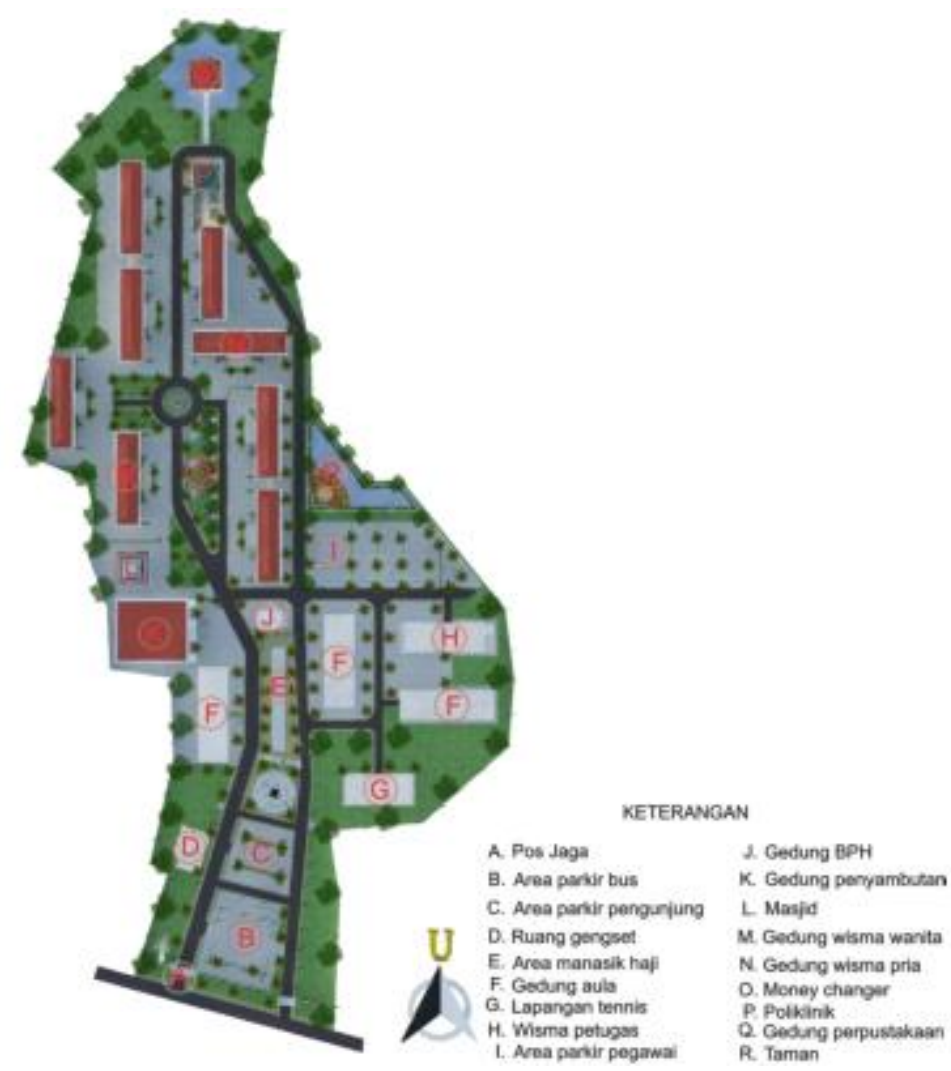

Gambar 12. Site Plan Kawasan

(Sumber : Olah Desain, 2017)

\section{Tampak Kawasan}

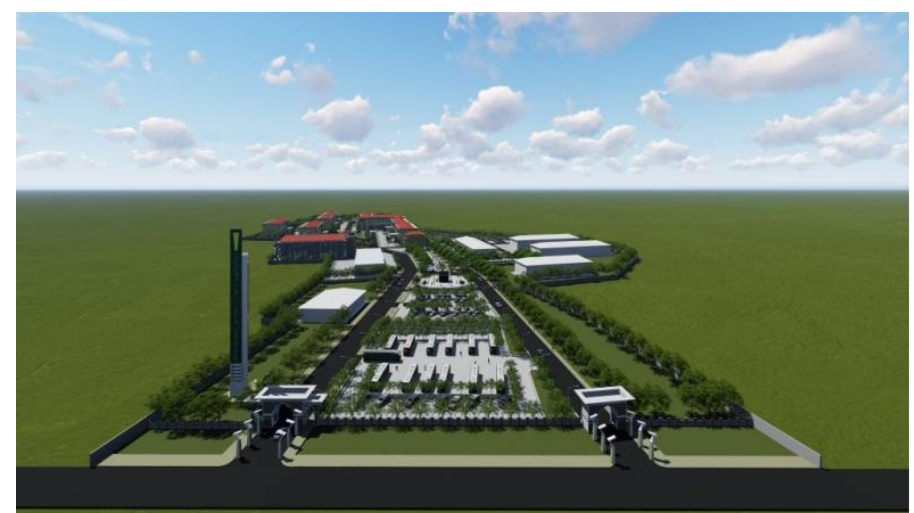

Gambar 13. View Utara Kawasan

(Sumber : Olah Desain, 2017) 
Irma Rahayu*,

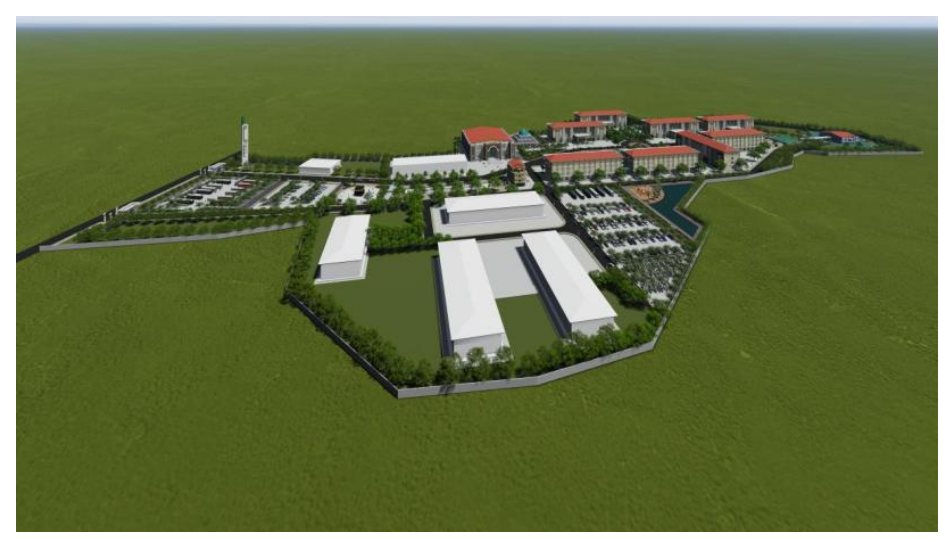

Gambar 14. View Timur Kawasan

(Sumber : Olah Desain, 2017)

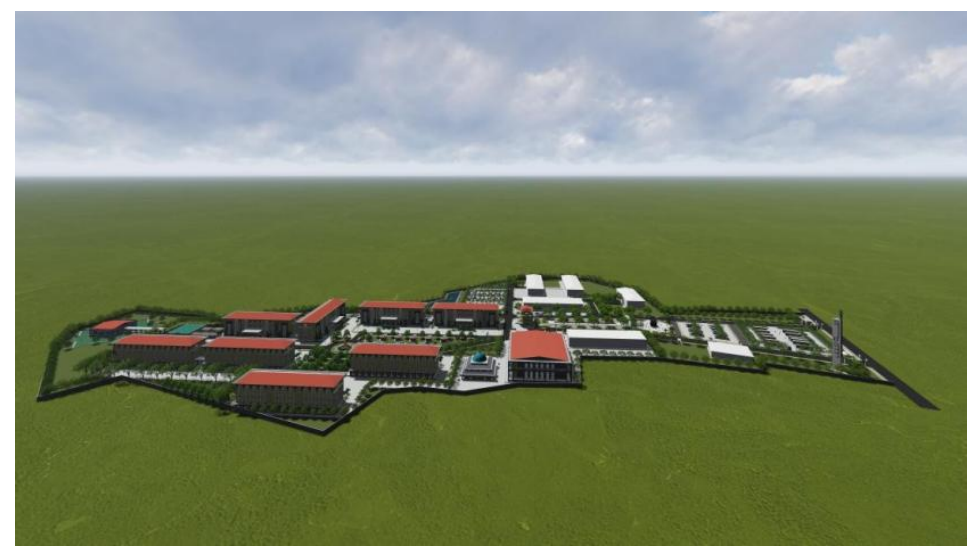

Gambar 15. View Selatan Kawasan

(Sumber : Olah Desain, 2017)

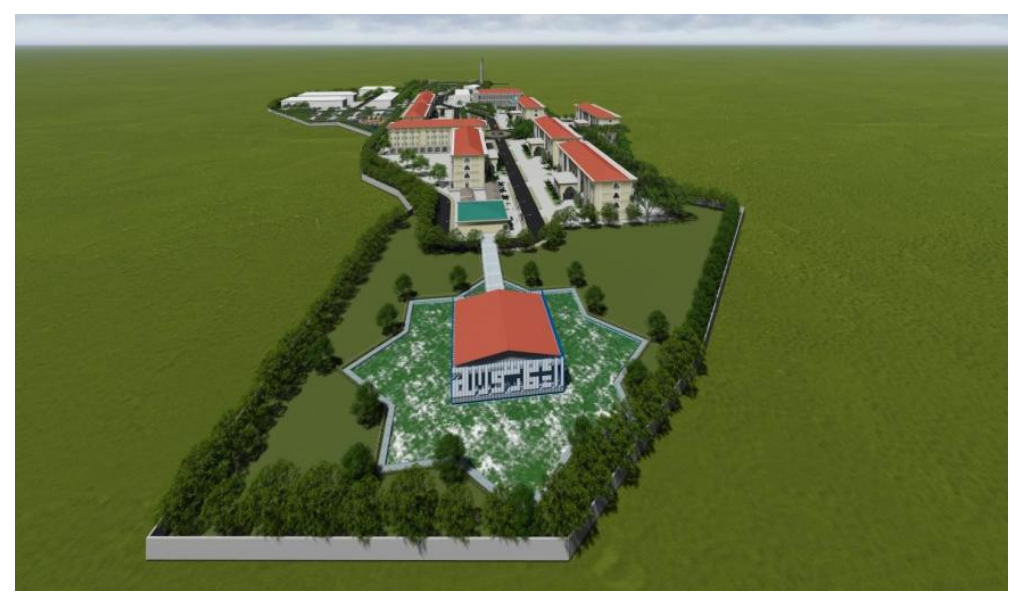

Gambar 16. View Barat Kawasan

(Sumber : Olah Desain, 2017) 


\section{J. Perspektif Bangunan}

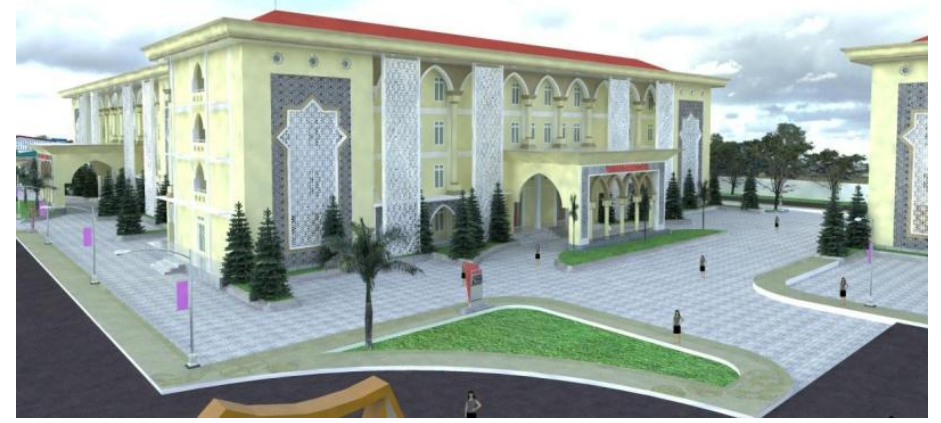

Gambar 17. Perspektif Gedung Wisma Haji (Sumber : Olah Desain, 2017)

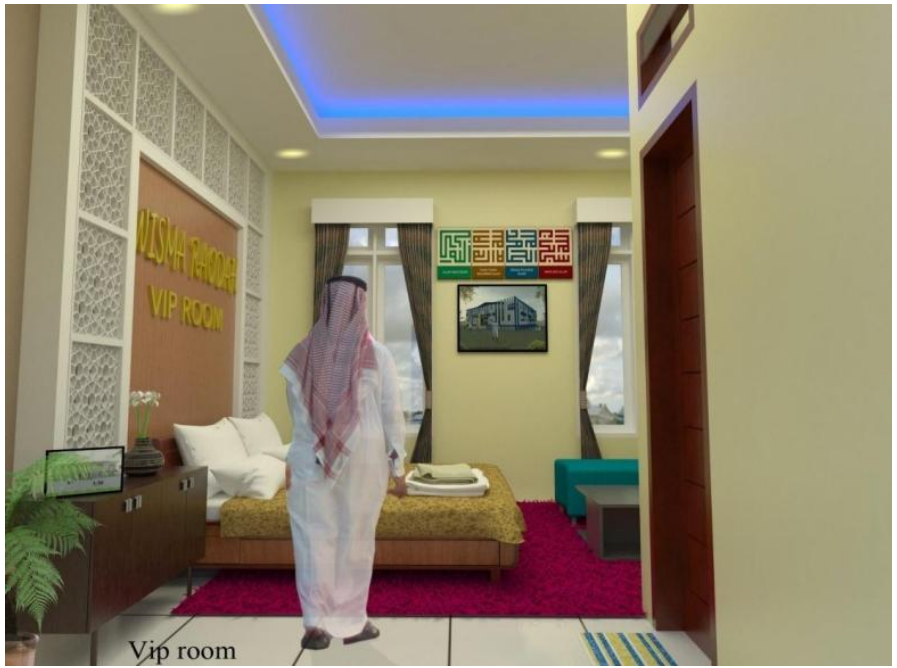

Gambar 18. Interior Kamar Tipe 1

(Sumber : Olah Desain, 2017)

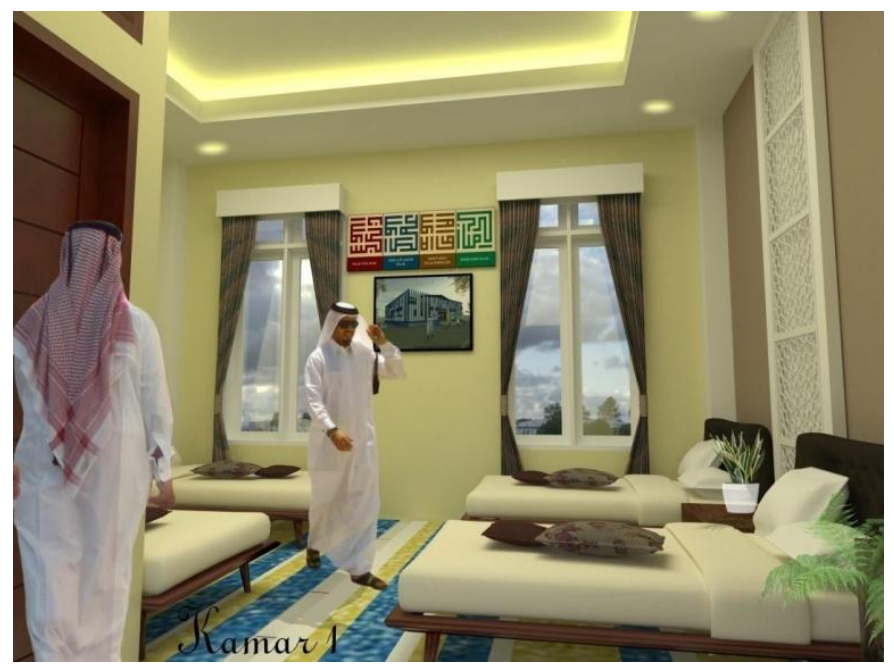

Gambar 19. Interior Kamar Tipe 2

(Sumber : Olah Desain, 2017) 
Irma Rahayu*,

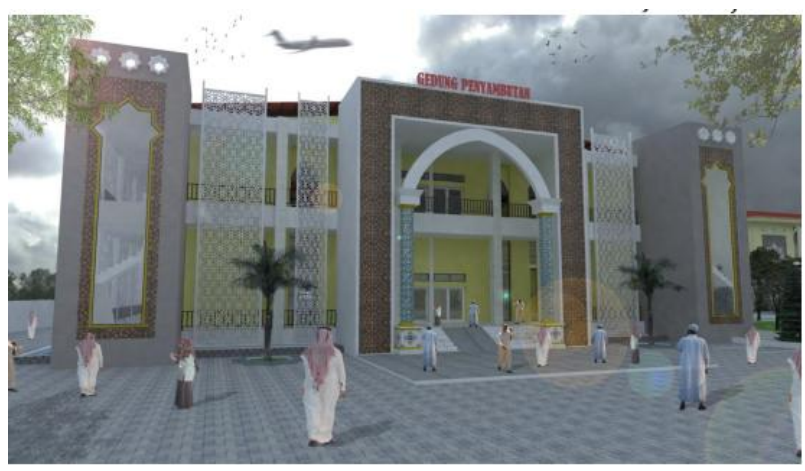

Gambar 20. Perspektif Gedung Penyambutan (Sumber : Olah Desain, 2017)

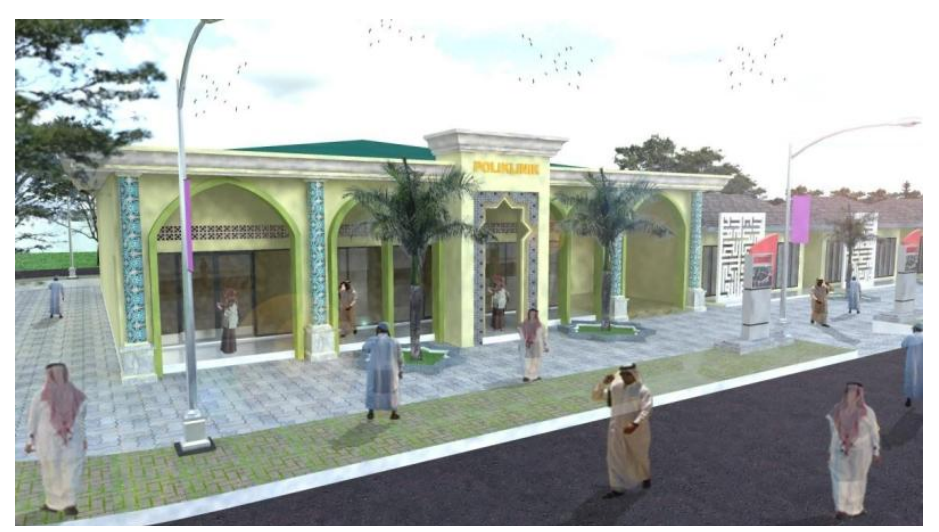

Gambar 21. Perspektif Poliklinik

(Sumber: Hasil Desain, 2017)

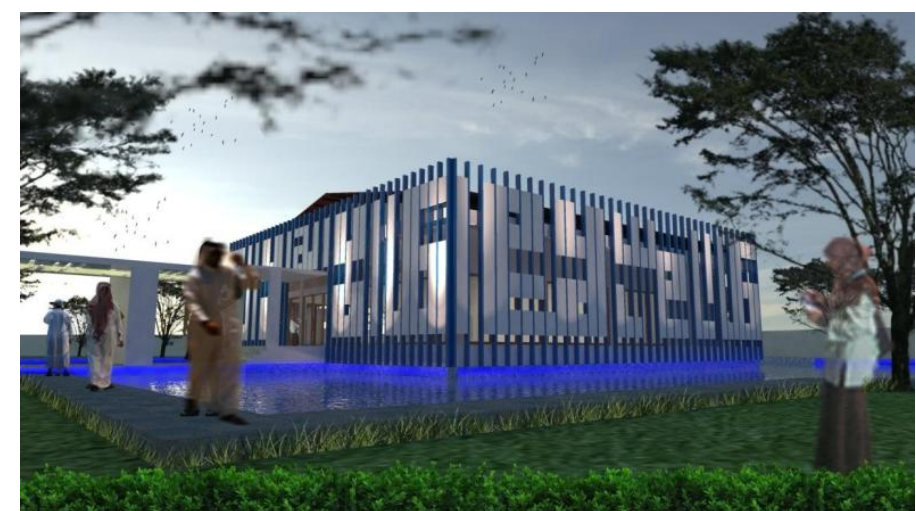

Gambar 24. Perspektif Gedung Perpustakaan (Sumber: Hasil Desain, 2017) 


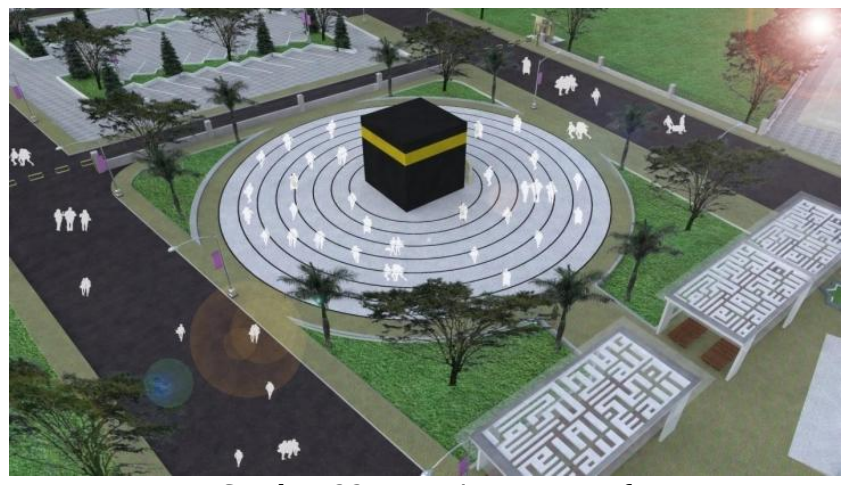

Gambar 22. View Area Tawwaf

(Sumber: Hasil Desain, 2017)

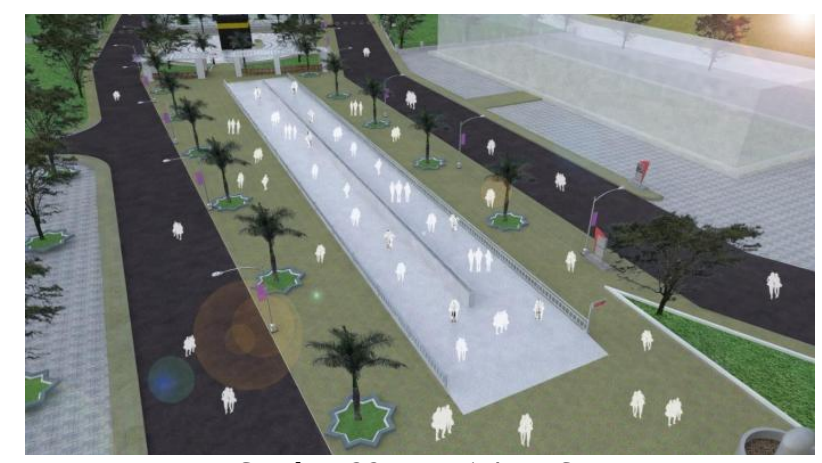

Gambar 23.View 1 Area Sai

(Sumber: Hasil Desain, 2017)

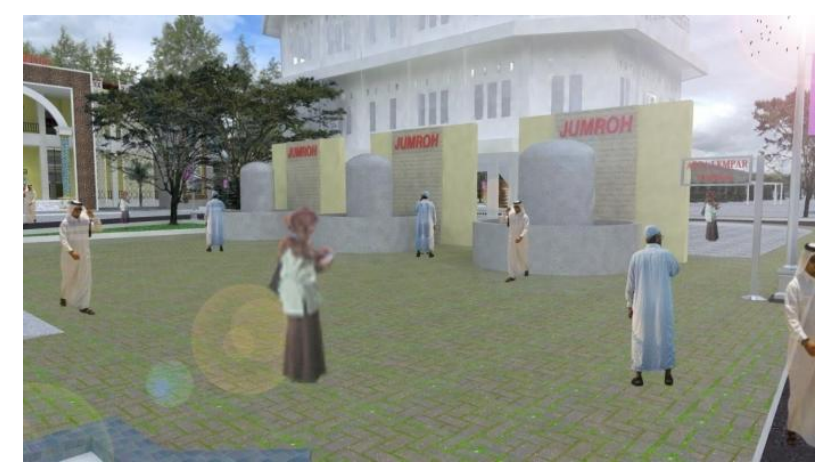

Gambar 24. View 2 Area Lempar Jumroh (Sumber: Hasil Desain, 2017)

Massa bangunan pada Asrama Haji ini sesuai dengan kelompok kegiatan yang ada, yakni massa bangunan pengelola, massa bangunan asrama, peragaan, dan massa bangunan penunjang. Setiap massa dihubungkan oleh elemen-elemen lansekap. Bentuk massa pada taman Asrama Haji ini dibuat sederhana, seperti bentuk -bentuk dasar seperti segitiga, lingkaran dan bujur sangkar untuk memudahkan sirkulasi dan efesiensi ruang -ruang yang ada.

Massa bangunan asrama dan peragaan merupakan bangunan utama dalam tapak, bentuk bangunan berfungsi sebagai point of interest pada tapak. Penataan Tapak dilakukan dengan 
menambah elemen serta memodifikasi bentuk agar elemen yang dipertahankan dapat saling menyatu dengan elemen lain pada tapak.

\section{Sirkulasi dan Parkir}

Sirkulasi di sekitar tapak cukup padat terkhusus di Jalan Asrama Haji dikarenakan jalan tersebut merupakan jalan utama masuk menuju ke lokasi tapak. Kepadatan kendaraan roda dua dan empat terjadi pada saat pagi dan sore hari.

Sistem Sirkulasi dan parkir dalam kawasan Asrama Haji Embarkasi menggunakan sistem 1 arah serta pola parkir miring 45 derajat untuk kendaraan roda empat dikarenakan pertimbangan kemudahan pengguna kendaraan, sedangkan untuk pengguna kendaraan bermotor menggunakan parkir tegak lurus. 


\section{DAFTAR REFERENSI}

Badan Pengelola Asrama Haji. (2013). Profil Asrama Haji Embarkasi Makassar.

De Chiara, Joseph \& Callendar, John. (1990). Time Saver Standards for Building Types 3rd edition , McGraw-Hill Publishing Company.

Gassing, Qadir dan Wahyudin Halim (2009). Pedoman Penulisan Karya Tulis Ilmiah. Makassar: Alauddin Press Makassar.

Lieberman, P. M. (1976). Personal Remembrance. SB 1976, hal 8.

Neufert,Ernest; (1997). Data Arsitek Jilid 1. Jakarta: Erlangga. Bany Chaerwansyah, dkk

Neufert,Ernest: (1997). Data Arsitek Jilid 2. Jakarta: Erlangga.

Neufert,Ernest. (1991). Architect's Data. Second. Dialihbahasakan oleh Sjamsu Amril. Jakarta: Erlangga,

Website:

http://sulsel.kemenag.go.id/index.php?a=berita\&id=273308/ (di akses tanggal 28-02-2016 pukul 16.10 WITA).

http://sulsel.bps.go.id/LinkTableDinamis/view/id/84 (di akses tanggal 28-02-2016 pukul 13.57 WITA).

http://www.dokumenpemudatqn.com/2013/07/persentase-jumlah-umat-islam-berbagai.html (di akses tanggal 28-02-2016 pukul 14.03 WITA).

http://haji.kemenag.go.id/v2/content/rata-rata-96-persen-pertahun-jemaah-berangkat-status-

belum-haji, (di akses tanggal 28 Februari 2016, pukul 1 16.10 WITA).

http://darimakassar.com/rtrw-kota-makassar-2010-2030-2/, (di akses tanggal 09 September 2016, pukul 15.40 WITA). http://haji.kemenag.go.id/v2/basisdata/waiting-list, (diakses tanggal 15 September 2016, pukul 14.17 WITA) http://arsitektur.blog.gunadarma. ac.id, (diakses 19 September 2016, pukul 14.30 WITA)

http://www.azhar.eg/hajj, (di akses 19 September 2016, pukul 14.17 WITA)

https://fihani.files.wordpress.com/2011/05/img00243-20110416-09411.jpg, (di akses 19 September 2016, pukul 14.40 WITA)

https://awasdez.wordpress.com/2013/02/12/ karakteristik-bangunan-pada-arsitektur-islam/, di akses 19 September 2016, pukul 14.30 WITA) http://www.islamiclandmarks.com/wpcontent/uploads/2016/01/Masjid-Quba-front.jpg, (di akses 19 September 2016, pukul 14.20 WITA)

http://log.viva.co.id/news/read/717369-tiga-keutamaan-berziarah-ke-makam-rasulullah-saw,(di akses 19 September 2016, pukul 17.40WITA)

www.google earth.com (di akses 21 September 2016 pukul 14.40 WITA, 10 Maret 2017, pukul 13.30 WITA)

http://www.epalembang.com/lang/id/service/government/palembang-hajj-dormitory/ (di akses 21 September 2016, pukul 14.40 WITA)

http://asramahaji.esy.es/, ( di akses 21 September 2016, pukul 11.40 WITA) http://www.darimakassar.com/2013/02/09/rtrw-kota-makassar-2010-2030-2/,2017 (10 Maret 2017, pukul 13.30 WITA) http://komunitas-atlas.blogspot.co.id/2012/08/ kecamatan-biringkanaya.html, 2017 (10 Maret 2017, pukul 13.30 WITA) 